\title{
Desintensificação do uso da terra e sua relação com a erosão do solo
}

\author{
Alexandre ten Caten ${ }^{1}$, Jean P. G. Minella ${ }^{2}$ \& Pedro R. de A. Madruga ${ }^{3}$
}

\begin{abstract}
RESUMO
A conservação dos recursos naturais tais como solo e água, deve ser preocupação de governos e instituições. Processos erosivos são responsáveis pela degradação desses recursos, em várias partes do globo. Objetivou-se, com este estudo, avaliar a dinâmica da cobertura da terra em uma região de topografia complexa e empregar a equação universal de perda de solos modificada (RUSLE) para quantificar a perda de solos em decorrência da erosão. O uso da terra no distrito de Vale Vêneto, município de São João do Polêsine na região central do Estado do Rio Grande do Sul, foi avaliado em imagens Landsat nos anos de 1988, 2000 e 2007. A análise espaço temporal do uso da terra indica que as áreas de floresta tiveram um aumento de $16,2 \%$ no período de 19 anos. As áreas de agricultura sofreram uma diminuição de 57,5\%, no mesmo período. A erosão bruta específica sofreu uma redução de 44\%, de 1988 a 2007. Verificou-se que a desintensificação do uso da terra leva a uma configuração mais favorável de conservação do solo e mitigação da erosão. É provável que as mudanças ocorridas no uso da terra estejam relacionadas à não reprodução das famílias rurais que, anteriormente, cultivavam áreas impróprias para a atividade agrícola nesta região.
\end{abstract}

Palavras-chave: equação universal de perda de solo, sistema de informação geográfica, bacia hidrográfica

\section{Disintensification of land use and its relation with soil erosion}

\begin{abstract}
Conservation of natural resources such as soil and water should be a concern of governments and institutions. Erosion processes are responsible for the degradation of these important resources in many parts of the globe. The aim of this study was to assess the land cover dynamics in a region of complex landscape and employ the modified universal soil loss equation (RUSLE) to quantify soil loss due to erosion. The land use in the district of Vale Veneto, São João do Polêsine in central region of Rio Grande do Sul, was evaluated in Landsat images of 1988, 2000 and 2007. The spatial and temporal analysis of the land use indicates that the forest areas had a $16.2 \%$ increase over the 19 years period. Areas under agriculture had a decrease of $57.5 \%$ over the same period. The gross erosion suffered a $44 \%$ reduction from 1988 to 2007 . The study showed that land use disintensification leads to a more favorable configuration for soil conservation and erosion mitigation. It is believed that changes in land use are related to diminishing number of rural families who previously cultivated areas unsuitable for agriculture in this region.
\end{abstract}

Key words: universal soil loss equation, geographic information systems, watershed 


\section{INTRODUÇÃO}

A erosão é um fenômeno cujo impacto sobre os recursos naturais, especialmente solo e água, tem preocupado governos e instituições em todo o mundo (Minella et al., 2008). O uso sustentável e a conservação dos recursos naturais para a produção de alimentos e a agricultura é um dos cinco pilares do planejamento estratégico 2000-2015 da FAO, destaque para a mitigação dos processos erosivos do solo. Os efeitos da erosão do solo têm sido considerados uma ameaça à própria existência da humanidade, contribuindo para a urgência de se quantificar e controlar as causas do processo erosivo (Albuquerque et al., 2005). Alguns locais do planeta, como o continente Africano, geram preocupação quanto à erosão (Angima et al., 2003) mas, felizmente, em outros a erosão tem diminuído, a exemplo do continente Europeu (Bakker et al., 2008).

A erosão é um processo no qual partículas de solo são desprendidas da matriz coesa de solo e em seguida carreadas na direção jusante, por um dos agentes de transporte (Minella et al., 2007). Por ocasião de eventos de chuva o material do solo pode ser desprendido pelo impacto da gota de chuva ou pelo fluxo em superfície (Kinnell, 2010). Um dos fatores chave influenciando a suscetibilidade regional à erosão do solo é o uso da terra (Minella et al., 2007). Mudanças naturais e as provocadas pelo homem na cobertura do solo podem resultar na mitigação ou no aumento da erosão do solo (Cebecauer \& Hofierka, 2008). A desintensificação do uso da terra frequentemente implica em regeneração da cobertura natural ou na conversão de uma cobertura de baixo nível de proteção (agricultura) para coberturas de maior nível de proteção (floresta) (Bakker et al., 2008). Desta forma, a desintensificação do uso da terra pode ser benéfica para a redução da erosão e exportação de sedimentos para rios e lagos (Vanacker et al., 2005).

No sul do Brasil uma parcela significativa da agricultura familiar ocupa áreas de baixa aptidão agrícola e alta fragilidade ambiental (declividade acentuada das vertentes e solos rasos) (Pedron et al., 2006). A erosão hídrica é a principal consequência desta condição, que causa redução da capacidade produtiva dos solos e aumento da transferência de sedimentos e poluentes para os corpos de água (Minella et al., 2007).

Nos anos noventa a abertura econômica resultou na perda de mercado para os agricultores familiares, sobretudo para aqueles que não conseguiram se integrar às indústrias. Nas regiões que apresentam condições naturais desvantajosas e que não conseguiram competir com os grandes produtores internacionais, o homem do campo foi obrigado a traçar novas estratégias para não sucumbir às pressões externas, o que promoveu o deslocamento dos trabalhadores rurais para outras atividades (Perestrelo \& Martins, 2003). Após 1965, quando a população urbana ultrapassou o quantitativo de pessoas que moram nas áreas rurais do estado, a população urbana cresceu de forma constante mas atualmente menos que $15 \%$ da população do Rio Grande do Sul vivem em áreas rurais do estado, segundo a Secretaria de Planejamento e Gestão do Estado do Rio Grande do Sul.
Na região da 4 a Colônia de Imigração Italiana do Rio Grande do Sul, RS, informações da prefeitura municipal de São João do Polêsine dão conta de que em 1970 a população do município era de 2.997 pessoas; quatro décadas depois, em 2010, a população do município reduziu em $13 \%$ para 2.633 pessoas dentre as quais $61 \%$ vivem na área rural do município; concluise, então, que as mudanças na demografia da população rural têm reflexo no uso da terra. O inventário florestal contínuo do Estado do Rio Grande do Sul realizado pela Secretaria do Meio Ambiente demonstra que ocorreu um aumento da cobertura florestal natural de 1982 para o ano 2000, de 11,91\%. A floresta natural passou de $15.857,31 \mathrm{~km}^{2}(5,62 \%)$ em 1982 para 49.556,29 $\mathrm{km}^{2}(17,53 \%)$ em 2000 .

Estudos realizados na região central do estado em área do Rebordo do Planalto têm demonstrado um aumento de usos mais conservacionistas como a floresta. Em estudo da cobertura da vegetação na microbacia de Arroio Grande, nos municípios de Itaara e Santa Maria, Ruhoff (2004) diagnosticou um aumento de 51,90 para 58,50\% da área com cobertura florestal, nos anos de 1987 a 2002. No seu estudo, Miguel (2009) verificou aumento em $11 \%$ no uso floresta, de 1987 para 2009, além de um decréscimo em $8 \%$ nas áreas de lavoura neste mesmo período, na Bacia de Captação da Barragem do DNOS/CORSAN, Santa Maria. Ainda segundo o autor, muitas das áreas de floresta, principalmente ao longo do Rebordo do Planalto, foram desmatadas para ceder lugar à agricultura e pastagem, implantadas durante a colonização da região. Nos últimos anos essas áreas foram abandonadas, pela dificuldade de mecanização, perda de fertilidade e erosão, levando a vegetação natural a se restabelecer.

Modelos para estimativa da erosão são utilizados com frequência para determinar o efeito da rotação de culturas na erosão do solo e identificar alternativas que possam auxiliar na redução da produção de sedimentos. Como tal, tais modelos se constituem em ferramentas auxiliares à tomada de decisão na identificação e adoção de práticas conservacionistas do solo e da água. Em geral, modelos empíricos têm estrutura muito simplificada pois requerem menor quantidade de dados e, comumente, demonstram uma performance similar, em termos de acurácia, aos modelos determinísticos quando considerados em bases anuais de predição (Schiettecatte et al., 2008).

A equação universal de perda de solos revisada (Revised Universal Soil Loss Equation - RUSLE) é um modelo empírico para erosão do solo desenvolvido a partir da equação universal de perda de solos (Universal Soil Loss Equation - USLE). Este modelo é capaz de apresentar a heterogeneidade espacial da erosão do solo e, por ser desenvolvido convenientemente em Sistemas de Informação Geográfica (SIG), tem sido o modelo empírico para predição da erosão do solo mais amplamente utilizado no planeta (Yue-Qing et al., 2008).

A hipótese deste trabalho é a de que está ocorrendo uma desintensificação do uso da terra na área de estudo, com a substituição de usos com maior poder erosivo (agricultura) por outros mais conservacionistas (floresta). Esta desintensificação do uso estaria associada a mudanças na principal atividade econômica da área de estudo, isto é, a agricultura em pequenas propriedades, haja vista que com a desintensificação do uso estaria ocorrendo redução no potencial erosivo. 


\section{Material e MÉTODOS}

A área do estudo foi a bacia hidrográfica do distrito de Vale Vêneto, entre os municípios de Silveira Martins e São João do Polêsine, na região central do RS, com uma área de $46,3 \mathrm{~km}^{2}$ (Figura 1). Segundo a classificação climática de Köppen, o clima se enquadra em temperado chuvoso e quente do tipo Cfa, com temperatura média anual mínima de 14 e máxima de 25 ${ }^{\circ} \mathrm{C}$. A média anual de precipitação é de 1600 mm, não ocorrendo estação de seca definida. A média mensal de umidade relativa é de $80 \%$ (Klamt et al., 1997).

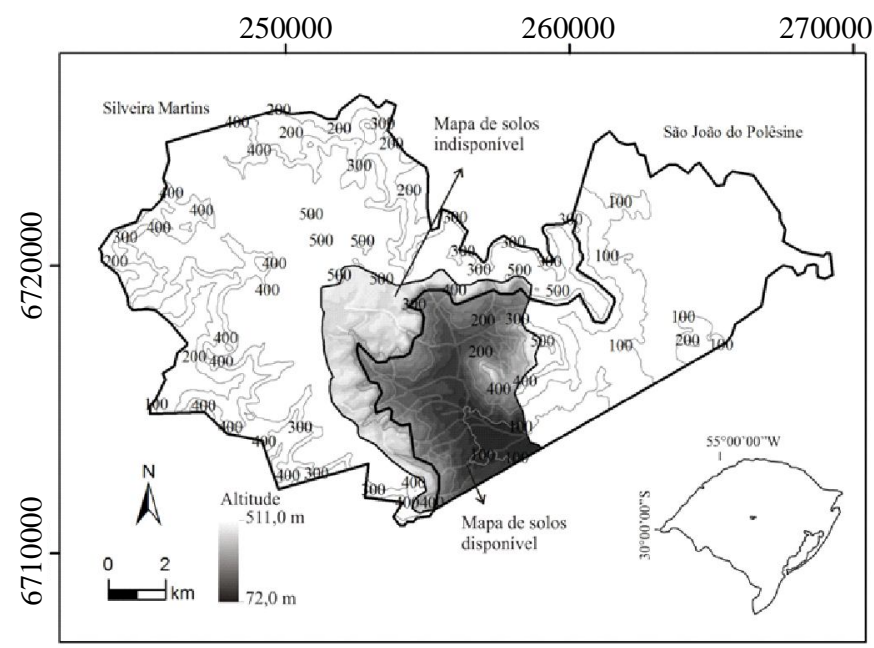

Figura 1. Área de estudo localizada entre os municípios de Silveira Martins e São João do Polêsine, na região central do Estado do Rio Grande do Sul

Na região fitoecológica da área estudada encontra-se a Floresta Estacional Semidecídua, sendo o frio o responsável pela estacionalidade fisiológica das plantas. Neste conjunto florestal se encontram, na época desfavorável, até $50 \%$ de árvores caducifólias. A região está subdividida em três formações utilizando-se, basicamente, critérios altimétricos: floresta fluvial, floresta submontana (30 a $400 \mathrm{~m}$ ) e floresta montana (> $400 \mathrm{~m}$ ) (Klamt et al., 1997).

O local do estudo se situa na transição da Depressão Central Gaúcha com a Encosta Inferior do Nordeste. Nesta área estão presentes os morros residuais, constituídos de rochas vulcânicas da formação Serra Geral com arenitos eólicos intertrápicos, acima de $200 \mathrm{~m}$. Nesta área são comuns declividades entre $20^{\circ}(36 \%)$ e $50^{\circ}(119 \%)$, o que dificulta seu uso para atividades agropecuárias. Abaixo de $200 \mathrm{~m}$ se encontra a Depressão Central ou Periférica, formada por rochas sedimentares da Bacia do Paraná (Klamt et al., 1997).

A vulnerabilidade a degradação da terra na região do Rebordo do Planalto do Rio Grande do Sul (RS) foi reconhecida por Stürmer et al. (2009). Esta vulnerabilidade se deve à complexidade geomorfológica da região, o que lhe confere alto potencial de geração de sedimentos, mesmo sob condições naturais e, com isto, o relevo é mantido sob um processo de rejuvenescimento permanente. Apesar dessa vulnerabilidade, a região vem sendo explorada, há vários anos, com vista à produção agropecuária, sendo frequente a exploração agropecuária em locais inadequados (Pedron et al., 2006). A economia local se baseia, sobretudo, no setor primário, onde a maioria das propriedades se caracteriza por minifúndios e pela diversificação de culturas, destacando-se arroz irrigado, milho, feijão, soja e fumo. A área média das propriedades é de 20 ha (Klamt et al., 1997).

As informações acerca das classes de solos encontradas na área do estudo foram obtidas de levantamento pedológico realizado por Klamt et al. (1997) em escala 1:20.000, no local em que são encontradas as associações entre Argissolos, Cambissolos e Neossolos Litólicos nas coxilhas e áreas de encosta. Próximo à rede de drenagem se destacam os Gleissolos Háplicos e os Planossolos Hidromórficos. Parte da bacia hidrográfica permanece dentro do município de Silveira Martins no qual não há levantamento de solos disponível na escala de detalhamento; para esta área a classe de solo foi determinada por aproximação àquelas em mesma posição e, portanto, com iguais relações solo-paisagem da área mapeada em São João do Polêsine.

A região do Rebordo do Planalto se configura, então, em uma área de grande complexidade geomorgológica (Pedron et al., 2006) e que refletiu na sua ocupação e no uso da terra, ao longo desses anos, desde a colonização (Miguel, 2009). A quantificação do potencial erosivo da área e dos locais em que este processo, é mais intensa e muito importante para a exploração adequada dos recursos naturais. O uso de modelos como o RUSLE tem o potencial não apenas de quantificar esses processos erosivos mas também de identificar as áreas e os efeitos da ação antrópica que estejam potencializando tais danos ambientais, ao longo do tempo (Kinnell, 2010). É importante salientar que este modelo estima a erosão associada aos processos de erosão entressulco e em sulco não englobando, obviamente, outros processos erosivos que ocorrem nesta bacia, por exemplo, a erosão fluvial.

Considerando os dados disponíveis, o tamanho da bacia hidrográfica e a proposta do estudo, o modelo RUSLE foi utilizado para analisar o efeito das mudanças ocorridas na área do estudo, o qual foi desenvolvido para predizer a erosão bruta média anual através da Eq. 1.

$$
\mathrm{A}=\mathrm{R} \times \mathrm{K} \times \mathrm{L} \times \mathrm{C} \times \mathrm{P}
$$

em que:

A - perda de solos média por unidade de área, em decorrência da erosão em sulco e entressulco, $\mathrm{t} \mathrm{ha}^{-1} \mathrm{ano}^{-1}$

$\mathrm{R}$ - fator de erosividade da chuva, $\mathrm{MJ} \mathrm{mm} \mathrm{ha} \mathrm{m}^{-1} \mathrm{~h}^{-1} \mathrm{ano}^{-1}$

$\mathrm{K}$ - fator de erodibilidade do solo, $\mathrm{t}$ ha $\mathrm{h} \mathrm{MJ}^{-1} \mathrm{ha}^{-1} \mathrm{~mm}^{-1}$

L - fator comprimento de rampa

$\mathrm{S}$ - fator declividade de rampa

C - fator de cobertura e práticas de manejo do solo

$\mathrm{P}$ - fator de práticas conservacionistas

As variáveis L, S, C e P são redutoras configuradas para o valor 1 (unidade) em experimentos realizados em parcela padrão; consequentemente, esses valores são adimensionais. O RUSLE, versão revisada da USLE (Wischmeier \& Smith, 1978), foi desenvolvida para dar conta dos conhecimentos e dados acumulados nos anos 80 e 90 do século 20. Esta equação prediz 
perda anual média de solos em longo prazo, associada com a erosão entressulco e em sulcos, utilizando-se de seis fatores associados ao clima, solo, topografia, vegetação e manejo. Quando implementada em grandes áreas, diferente da parcela padrão de 22,1 m (L) e $9 \%$ (S), como diversidade de sistemas agrícolas, existe tendência dos modelos USLE e RUSLE em superestimarem os valores mais baixos de perda de solos anual média e subestimar os valores mais elevados de perda de solos anual média (Kinnell, 2010).

Todos os fatores do RUSLE foram calculados em SIG, com dados meteorológicos, modelos digitais de terreno, mapas de solos e de uso da terra, processados no programa ArcGIS 9.3. Foram utilizadas matrizes de dados com resolução de $30 \mathrm{~m}$, sendo esta a resolução do Modelo Digital de Elevação derivado para a área, a partir do banco de dados Topodata, disponível em http://www.dpi.inpe.br/topodata.

$\mathrm{O}$ fator R quantifica o efeito do impacto da chuva e reflete a quantidade e a taxa de escoamento associadas a eventos de precipitação. A erosividade foi extraída do estudo realizado por Santos (2008) sobre a erosividade das chuvas no Estado do RS, para eventos de El Niño e La Niña e períodos normais; para o presente estudo foi utilizado o valor de $8.000 \mathrm{MJ} \mathrm{mm}$ $\mathrm{ha}^{-1} \mathrm{~h}^{-1}$ ano $^{-1} \mathrm{em}$ toda a área de $46,3 \mathrm{~km}^{2}$; este valor representa a erosividade de anos ditos neutros, de La Niña e indeterminados, definidos por Santos (2008) a partir de dados de 91 estações pluviométricas espalhadas pelo Estado.

A erodibilidade é a taxa de perda de solos por unidade do índice de chuva; originalmente, o fator $\mathrm{K}$ era determinado pela divisão dos valores de $\mathrm{A}$, determinado em experimentos de perda de solos, por R; neste estudo utilizou-se a Eq. 2 (Wischmeier \& Smith, 1978) uma vez que todos os parâmetros necessários para este modelo podem ser encontrados no relatório do levantamento de solos, realizado por Klamt et al. (1997) na área do estudo.

$$
\mathrm{K}=2,1 \times 10^{4} \times(12 \mathrm{MO}) \times \mathrm{M}^{1,14}+3,2 \times(\mathrm{s} 2)+(\mathrm{p} 3) \times 100
$$

donde:

\section{MO- matéria orgânica do solo}

M - representa o produto de partículas primárias do solo (areia, silte e argila)

s - classe estrutural do solo

p - classe de permeabilidade

No RUSLE valores de LS refletem o efeito da topografia na erosão do solo. O comprimento da rampa (fator L) representa o efeito do comprimento da declividade na erosão e o valor de declividade (fator $S$ ) reflete a influência do gradiente da declividade na erosão. Valores de LS foram gerados a partir de um modelo digital de elevação obtido a partir de dados SRTM processados e disponíveis no banco de dados Topodata. Segundo Okalp (2005) valores mais adequados para o fator LS seriam obtidos por medidas a campo; no entanto, como o intuito deste estudo não é determinar os valores absolutos de erosão mas, sim, a maneira como os valores relativos têm sido afetados pelas mudanças de uso da terra na região; acredita-se que a utilização do modelo proposto por Moore et al. (1993) seja válida para os propósitos deste trabalho.
O fator C é utilizado para refletir o efeito do uso da terra e do manejo do solo na erosão; ele é, também, a razão entre a perda de solos de longo prazo em uma área vegetada em relação à perda de solos de uma área desnuda de mesmo solo, cultivada na direção do movimento da água com $22 \mathrm{~m}$ de comprimento e de $9 \%$ de declividade. Originalmente determinada em experimentos de longo período de duração sob chuva natural, foi mais tarde identificado que o efeito de proteção acarretado pela vegetação varia ao longo do ano, de tal forma que o efeito do fator $\mathrm{C}$ seria a resultante de uma série de subfatores.

Neste estudo imagens obtidas pelo satélite Landsat 5 sensor TM nos anos de 1988, 2000 e 2007, todas na estação de inverno, foram utilizadas para gerar os mapas de classificação do uso da terra na área de estudo. O processamento das imagens foi realizado com o programa SPRING 5.1. Foram identificados os usos de floresta, agricultura, campo e água, nas três épocas classificadas de 1988, 2000 e 2007 e a esses usos foram atribuídos valores do fator $\mathrm{C}$ de acordo com Morgan (2005) de 0,001; 0,2; 0,025 e 0,0 para floresta, agricultura, campo e água, respectivamente.

O fator P é a razão da perda de solos com práticas específicas de conservação do solo em relação à perda correspondente, provocada por cultivos morro acima e morro abaixo. No presente estudo o valor de $\mathrm{P}$ foi utilizado como sendo $1 \mathrm{de}$ vez que não foi realizado um levantamento específico com a finalidade de quantificar o percentual de propriedades ou de áreas atingidas por práticas de conservação, embora seja importante ressaltar que na região é possível visualizar a adoção de práticas de conservação do solo pelos agricultores, com especial destaque para a presença de terraços e o plantio em nível.

No ambiente SIG todos os fatores do modelo RUSLE foram integrados visando quantificar a erosão bruta média anual para a área de estudo. Os fatores erosividade, erodibilidade, comprimento de rampa, declividade e práticas conservacionistas, foram mantidos constantes ao longo do período analisado de 19 anos. O fator cobertura do solo variou conforme os usos identificados para os anos de 1988, 2000 e 2007. Em decorrência das mudanças no uso da terra foi identificado o potencial erosivo da bacia hidrográfica, neste período.

\section{RESULTADOS E DISCUSSÃo}

A partir das informações dos perfis descritos no levantamento semidetalhado realizado por Klamt et al. (1994) foram possíveis o emprego da Eq. 1 e a geração da distribuição espacial do fator erodibilidade para a área de estudo, Figura 2A. Os valores constatados variaram de 0,0308 a $0,0671 \mathrm{t} \mathrm{ha} \mathrm{h}$ $\mathrm{MJ}^{-1} \mathrm{ha}^{-1} \mathrm{~mm}^{-1}$, para Argissolos Vermelhos-Amarelos e Argissolos Vermelhos, respectivamente. Referidos valores são compatíveis com os observados por Kinnell \& Risse (1998) em 14 localidades dos Estados Unidos a partir de dados do banco de dados utilizados para o desenvolvimento da USLE. Esses autores identificaram valores de $0,0345 \mathrm{t}$ ha $\mathrm{h} \mathrm{MJ}^{-1} \mathrm{ha}^{-1} \mathrm{~mm}^{-1}$ para solos argilosos e valores de $0,0270 \mathrm{t}$ ha $\mathrm{h} \mathrm{MJ}^{-1} \mathrm{ha}^{-1} \mathrm{~mm}^{-1}$ para solos de textura franco argilo arenosa. Um valor médio de 
A.

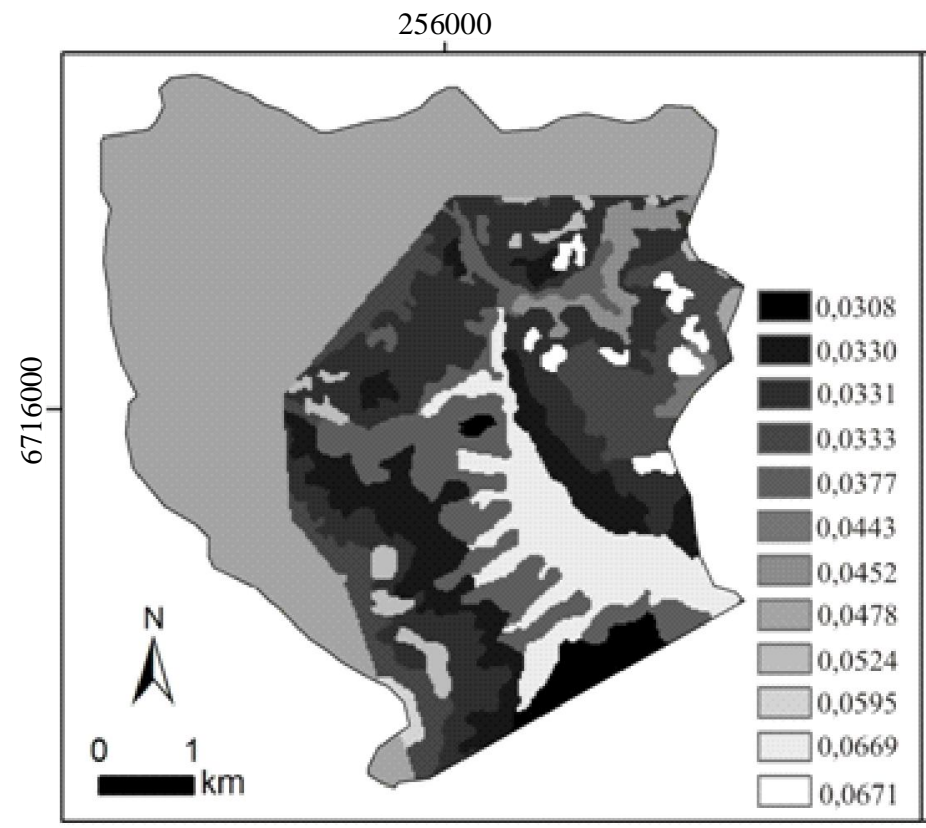

B.

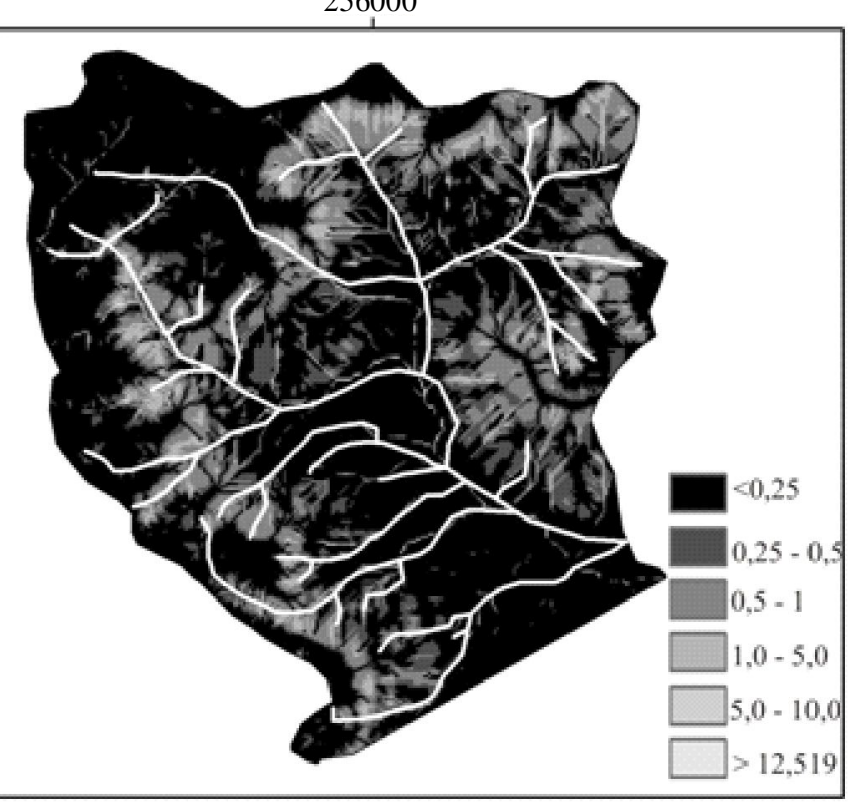

Figura 2. Fator erodibilidade do solo (t ha h MJ"-1 $\mathrm{ha}^{-1} \mathrm{~mm}^{-1}$ ) (A). Fator LS com a rede de drenagem sobreposta (B)

0,0388 tha h MJ $\mathrm{Ha}^{-1} \mathrm{~mm}^{-1}$ foi identificado por Yue-Qing et al. (2008) em áreas estudadas na China, onde não havia um levantamento de solos em escala de detalhe e o fator $\mathrm{K}$ foi determinado por aproximação com solos presentes no levantamento pedológico como sendo $0,0478 \mathrm{t}$ ha h $\mathrm{MJ}^{-1} \mathrm{ha}^{-1} \mathrm{~mm}^{-1}$ (sessão norte/noroeste do mapa na Figura 2A).

$\mathrm{O}$ fator declividade e o comprimento de rampa estão relacionados à topografia da área de estudo. Os maiores valores do fator LS foram observados nas áreas declivosas, como mostra a Figura 2B; o fator LS obteve valores próximos a zero em locais de terreno plano da Depressão Central e do Planalto. Entre essas duas áreas se localizam os maiores valores de declividade e, em contrapartida, os maiores valores do fator LS (Figura 2B).

Nas áreas de Encosta do Rebordo do Planalto a água adquire energia ao se deslocar sobre a paisagem, o que torna esta área a mais crítica, quanto ao potencial erosivo. Os valores do fator LS identificados neste estudo são similares aos reportados por Angima et al. (2003) em seu estudo em uma bacia hidrográfica do Kenya. Esses autores identificaram valores de LS variando de 0,8 até 23 , sendo os valores mais elevados associados às áreas mais declivosas. Por outro lado, valores de até 143 foram gerados em estudo realizado por Yue-Qing et al. (2008), embora os autores reportem que o valor médio encontrado tenha sido de 5,5 e que a maior parte da área é encontrada em valores de LS menores que 10.

A análise espaço temporal do uso da terra indica que, ao longo do período analisado, houve um incremento na área de floresta e diminuição considerável na área de agricultura, em decorrência de que o fator cobertura da terra se tem modificado na área de estudo (Figura 3). No início do período sob análise havia uma ampla área sob o uso agricultura (Figura 3A), que nos anos seguintes passou a ser substituída pelos usos campo e floresta (Figuras 3B e 3C). As áreas sob floresta ocupavam uma região visualmente menor, por volta de 1988, do que aquela encontrada em 2007, no final do período analisado (Figura 3C). Tal dinâmica do uso da terra irá implicar em mudanças no potencial erosivo na área de estudo em decorrência do efeito que a cobertura exerce no modelo RUSLE, notadamente em áreas declivosas.

As áreas de floresta tiveram um aumento de $16,2 \%$ no período de 19 anos. No ano de 2007 havia 2.512,8 ha sob o uso floresta. Por outro lado, as áreas de agricultura sofreram uma diminuição de 57,5\% no período, passando de 931,7 ha em 1988 para 395,9 ha em 2007 (Figura 4). Todas essas mudanças impactam, sobremaneira, o potencial erosivo uma vez que o uso da terra é determinante para a definição dos valores do fator C do modelo RUSLE. Esses resultados são corroborados por aqueles encontrados por Ruhoff (2004) e Miguel (2009), evidenciando que na região central do estado do RS a área de encosta do Rebordo do Planalto passa por uma mudança na cobertura da terra, de usos com maior potencial erosivo, para usos mais conservacionistas, como as florestas.

Todos os valores obtidos para os fatores $\mathrm{Ke} \mathrm{C}$ são assumidos como estimativas e, como a motivação principal deste estudo nãoé a obtenção de valores absolutos de erosão bruta mas, sim, sua dinâmica, ao longo dos anos, tornam-se importantes, para este estudo, os valores relativos para a análise temporal da erosão do solo, não sendo necessário que os valores de A sejam acurados mas que os valores espaços temporais sejam representados. De vez que os valores obtidos para os fatores $\mathrm{K}$ e C são boas representações da erodibilidade relativa de cada uso da terra, a natureza da resposta da erosão e exportação de sedimentos e as mudanças na cobertura da terra no tempo e no espaço, podem ser identificadas. Abordagem similar a esta fez com que Bakker et al. (2008) adotassem, preocupados com a produção de sedimentos, um estudo analisando a influência do uso da terra em áreas da Europa.

De posse dos valores de R, K, L, S e P constantes durante o período e do valor de $\mathrm{C}$, variável em decorrência da dinâmica 
A.

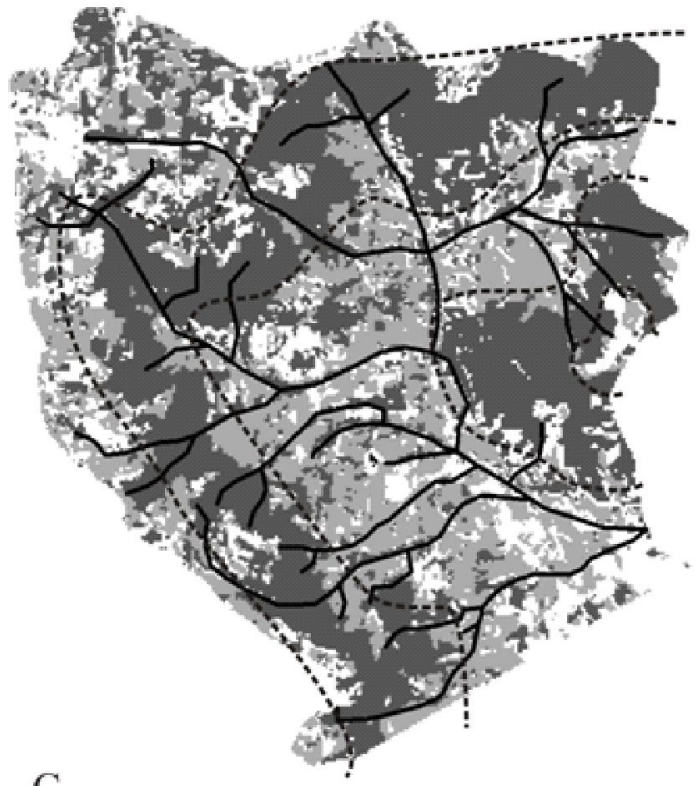

C.

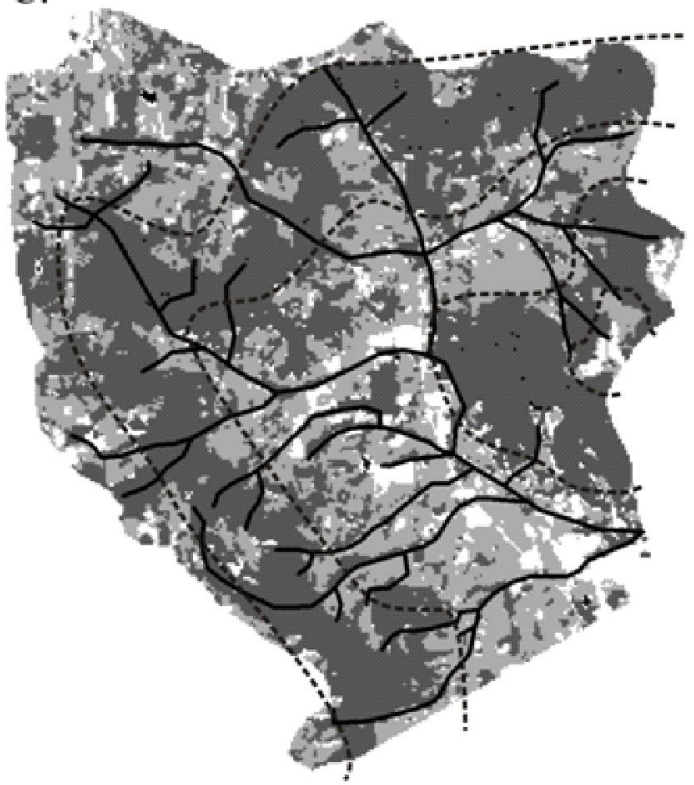

B.
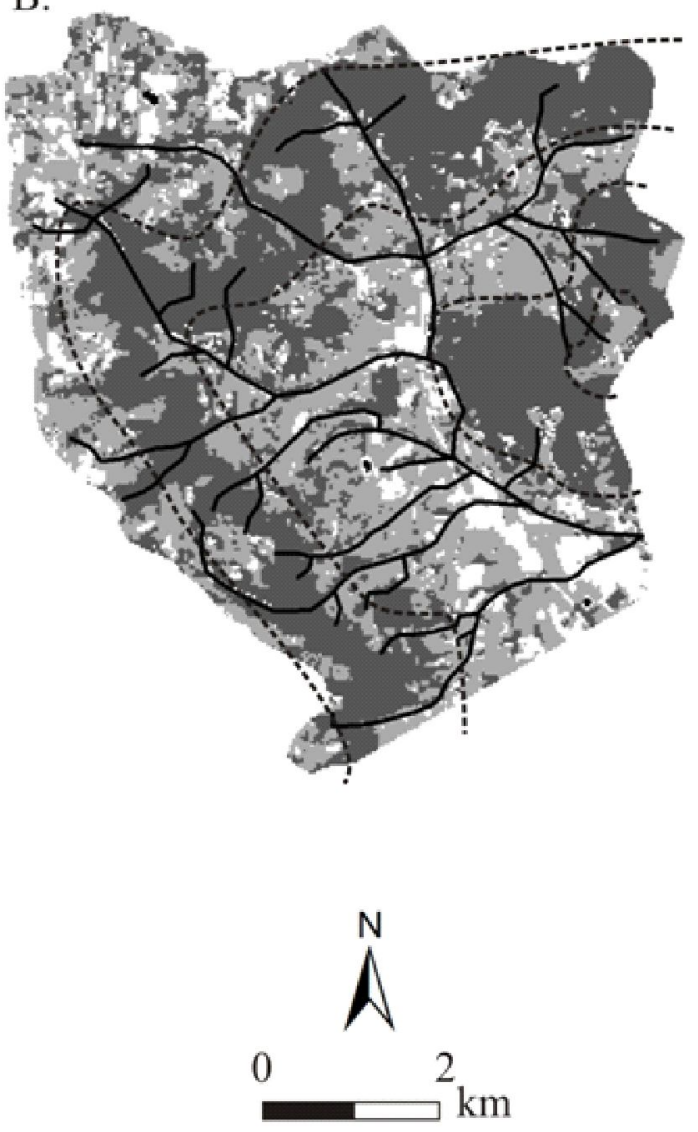

Fator C

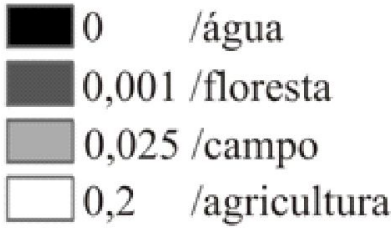

Figura 3. Dinâmica do fator C para a área de estudo nos anos de 1988 (A), 2000 (B) e 2007 (C). Áreas entre linhas tracejadas possuem valores de declividade entre 15 e $50^{\circ}$

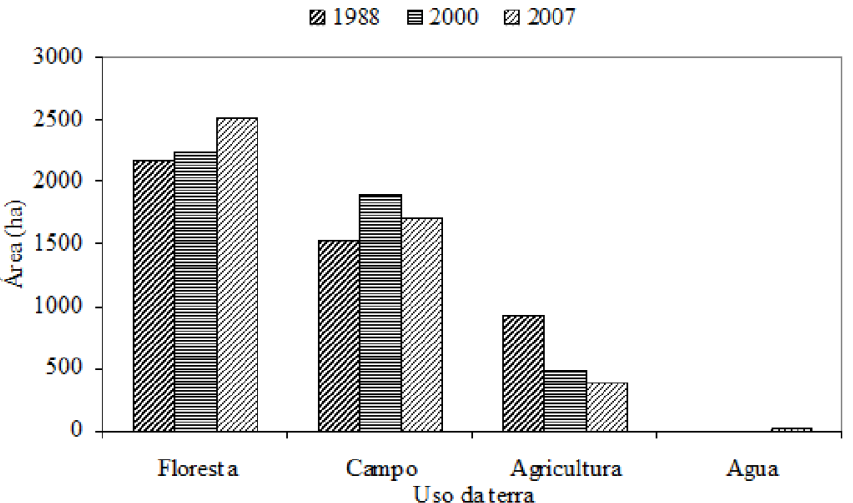

Figura 4. Mudança ocorrida nos quatros usos da terra identificados na área de estudo, no período de 1988 a 2007 do uso da terra, foi procedida a álgebra de matrizes pixel a pixel em um ambiente de Sistema de Informação Geográfica visando às determinação e distribuição espacial da erosão bruta média anual, na área de estudo.

A erosão bruta específica sofreu uma redução de $44 \%$ ao longo do período estudado, Tabela 1; em 1988 a estimativa da erosão bruta foi de $27 \mathrm{t} \mathrm{ha}^{-1}$ ano $^{-1}$ e após 19 anos a estimativa reduziu para $15 \mathrm{t} \mathrm{ha}^{-1}$ ano $^{-1}$ a alteração na erosão bruta também foi expressiva nos anos entre 1988 e 2000, quando houve redução de aproximadamente $10 \mathrm{t} \mathrm{ha}^{-1} \mathrm{ano}^{-1}$. Valores acima de $200 \mathrm{t} \mathrm{ha}^{-1} \mathrm{ano}^{-1}$ foram identificados e associados a locais com a prática de agricultura em lugares de grande declividade.

Os valores da Tabela 1 são compatíveis com valores da literatura. Bakker et al. (2008) reportaram uma diminuição de 48,8 para 20,5 t ha ${ }^{-1}$ ano $^{-1}$ na erosão em área estudada em 
Tabela 1. Separação da perda de solo por classe de erosão e a importância relativa na área da bacia hidrográfica nos anos de 2007,2000 e 1988

\begin{tabular}{|c|c|c|c|c|c|c|}
\hline \multirow{2}{*}{$\begin{array}{l}\text { Classe de erosão } \\
\left(t_{\text {h }}^{-1} a^{-1} a^{-1)}\right.\end{array}$} & $\begin{array}{l}\text { Erosão bruta } \\
\quad\left(\text { t ano }^{-1}\right)\end{array}$ & Área da bacia (\%) & $\begin{array}{l}\text { Erosão bruta } \\
\quad\left(\text { t ano-1 }^{-1}\right)\end{array}$ & Área da bacia (\%) & $\begin{array}{l}\text { Erosão bruta } \\
\quad\left(\mathrm{t}_{\text {ano }}{ }^{-1}\right)\end{array}$ & Área da bacia (\%) \\
\hline & \multicolumn{2}{|c|}{2007} & \multicolumn{2}{|c|}{2000} & \multicolumn{2}{|c|}{1988} \\
\hline $0-0,01$ & 21 & 13,10 & 20 & 11,73 & 18 & 10,78 \\
\hline $0,01-0,05$ & 211 & 14,81 & 186 & 12,88 & 179 & 12,36 \\
\hline $0,05-0,1$ & 413 & 10,95 & 378 & 9,99 & 368 & 9,70 \\
\hline $0,1-0,5$ & 3985 & 31,41 & 3993 & 31,26 & 3806 & 29,96 \\
\hline $0,5-1,0$ & 3551 & 9,61 & 3929 & 10,58 & 3273 & 8,83 \\
\hline $1,0-5,0$ & 16769 & 14,97 & 20002 & 17,67 & 20822 & 17,05 \\
\hline $5,0-20,0$ & 20072 & 4,20 & 23367 & 4,88 & 45745 & 8,88 \\
\hline $20,0-70,0$ & 13495 & 0,74 & 15012 & 0,83 & 36763 & 2,17 \\
\hline $70,0-200,0$ & 10405 & 0,19 & 9439 & 0,17 & 12718 & 0,25 \\
\hline$>200$ & 1235 & 0,01 & 4510 & 0,02 & 2293 & 0,02 \\
\hline $\begin{array}{l}\text { Erosão bruta específica } \\
\qquad\left(\mathrm{t} \mathrm{ha}^{-1} \mathrm{ano}^{-1}\right)\end{array}$ & \multicolumn{2}{|c|}{15,14} & \multicolumn{2}{|c|}{17,44} & \multicolumn{2}{|c|}{27,18} \\
\hline
\end{tabular}

Portugal. Esta diminuição na erosão, segundo os autores, esteve associada à mudança no uso da terra e consequente diminuição do fator C no modelo RUSLE utilizado, valores de $14,3 \mathrm{t} \mathrm{ha}^{-1} \mathrm{ano}^{-1}$ foram considerados baixos pelos autores. YueQing et al. (2008) classificaram baixa a classe 5,0-25,0 t ha $^{-1}$ ano $^{-1}$; esses autores relataram erosão bruta média de 28,7 $\mathrm{t} \mathrm{ha}^{-1} \mathrm{ano}^{-1}$ e valores extremos de até $200 \mathrm{t} \mathrm{ha}^{-1} \mathrm{ano}^{-1}$. Desta forma, a produção potencial atual de sedimentos, próxima a $15 \mathrm{t} \mathrm{ha}^{-1}$ $\mathrm{ano}^{-1}$ na área de estudo, pode ser considerada baixa, ou seja, compatível com os valores encontrados no cultivo em nível testado por Albuquerque et al. (2005) quando valores de 15,4 $\mathrm{t} \mathrm{ha}^{-1} \mathrm{ano}^{-1}$, foram medidos em áreas cultivadas com palma (Opuntia ficus-indica).

A análise da representatividade de cada uma das classes de erosão da Tabela 1 evidencia que, ao longo do período estudado, as classes de solos de menor erosão bruta apresentaram um incremento percentual em relação à área total da bacia, Figura 5A; as quatro menores classes utilizadas no
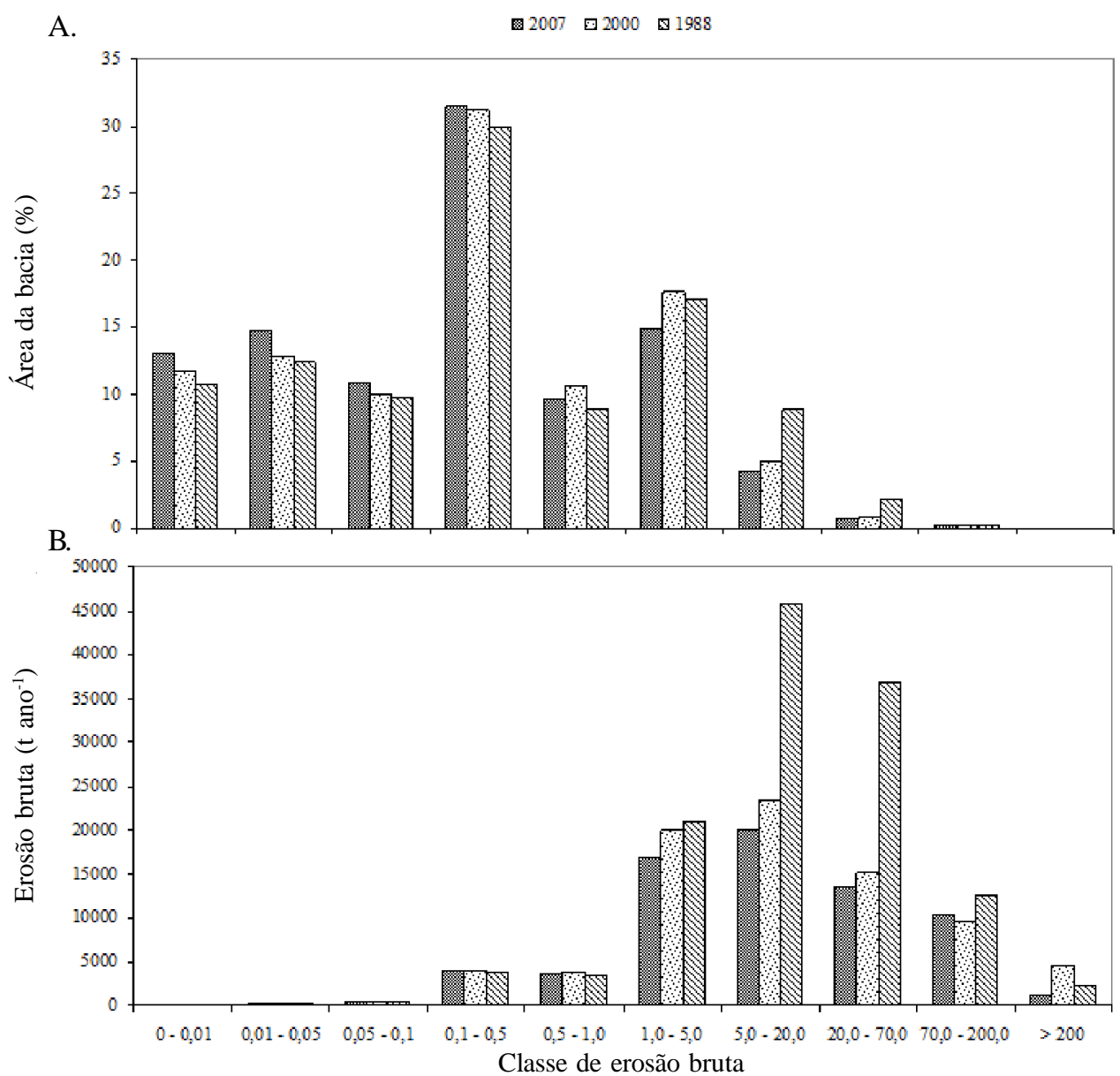

Figura 5. Área da bacia hidrográfica em cada uma das classes de solo no período estudado (A). Erosão bruta em cada uma das classes de solo nos anos de 1988, 2000 e 2007 (B) 
estudo, de 0-0,01 até 0,1-0,5 tha $\mathrm{ano}^{-1}$ experimentaram aumento de área, ou seja, a ocorrência dessas classes tornou-se mais frequente de 1988 para 2007; as quatro classes de erosão eram encontradas em 29,1 km² em 1988, passaram a 30,5 km² em 2000 e em 2007 a $32,5 \mathrm{~km}^{2}$ do total de $46,3 \mathrm{~km}^{2}$ da área da bacia hidrográfica.

Significativa também foi a mudança ocorrida nas maiores classes de erosão. As quatro maiores classes, acima de 5,0 $\mathrm{t} \mathrm{ha}^{-1}$ ano $^{-1}$, ocupavam $5,2 \mathrm{~km}^{2} \mathrm{em} 1988$ e passaram a $2,3 \mathrm{~km}^{2}$ em 2007. Esta diminuição de mais de 55\% na área ocupada pelas classes de maior erosão exerce grande impacto no potencial de degradação da área estudada. Em 1988 a classe de 5,0-20,0 t ha $^{-1}$ ano $^{-1}$ era responsável por um potencial de erosão de até $45.744 \mathrm{t} \mathrm{ano}^{-1}$ (Figura 5B). A erosão bruta média alcançava, nas cinco maiores classes em 1988, $23.667 \mathrm{t} \mathrm{ano}^{-1}$ e reduziu para $12.395 \mathrm{t} \mathrm{ano}^{-1} \mathrm{em} 2007$.

Em geral, desintensificação do uso da terra leva a uma configuração mais favorável de conservação do solo e menor produção de sedimentos; apesar disto, a dinâmica interna da cobertura do solo na região analisada pode resultar em valores inesperados. A simples conversão de áreas anteriormente utilizadas com agricultura para uso floresta pode, inclusive, resultar em incremento na produção de sedimentos devido aos locais nos quais referidas mudanças ocorrem (Bakker et al., 2008).

A verificação das mudanças ocorridas no uso da terra na classe de erosão bruta mais expressiva, 5,0-20,0 t ano-1, de acordo com a Figura 5B evidencia que, do total de $4,1 \mathrm{~km}^{2}$, em $1988,3,2 \mathrm{~km}^{2}$ estavam sob o uso de agricultura; ressalta-se que nesses locais o uso floresta não foi identificado para o ano de 1988, Tabela 2.

Tabela 2. Usos da terra nas áreas identificadas com erosão bruta da classe entre 5,0 - 20,0 t ano ${ }^{-1}$ no ano de 1988

\begin{tabular}{lrcc}
\hline \multirow{2}{*}{ Uso da terra } & \multicolumn{3}{c}{ Área (ha) } \\
\cline { 2 - 4 } & $\mathbf{2 0 0 7}$ & $\mathbf{2 0 0 0}$ & $\mathbf{1 9 8 8}$ \\
Agricultura & 56,07 & 57,33 & 326,52 \\
Campo & 189,09 & 234,09 & 83,61 \\
Floresta & 164,88 & 119,07 & 0 \\
\hline
\end{tabular}

Nos anos posteriores áreas até então utilizadas para agricultura passaram a sê-lo com campo e floresta. Nos anos de 2000 e 2007 os usos campo e floresta ocupavam, juntos, 3,5 $\mathrm{km}^{2}$, ou seja, $86 \%$ das áreas desta classe que em 1988 geravam até $45.744 \mathrm{t} \mathrm{ano}^{-1}$ de sedimentos, passaram por uma desintensificação do uso da terra. O uso de baixo nível de proteção (agricultura) foi substituído para coberturas de maior nível de proteção (campo e floresta).

Acredita-se que as mudanças no uso da terra (Figura 3) tenham relação com alterações sofridas pelas propriedades rurais nas quais a agricultura era praticada de maneira mais abrangente, no ano de 1988. Áreas de regeneração da floresta são perceptíveis na região de Vale Vêneto. Locais de grande declividade que já foram cultivados no passado, quando as famílias contavam com mais mão-de-obra e com uma rentabilidade maior pelos produtos agrícolas, agora estão sendo abandonados para a regeneração da floresta. Uma das prováveis causas do aumento das florestas pode ser devida ao processo de êxodo rural (Dill et al., 2004) em que parte das propriedades foi transformada em sítios de final de semana, lavouras e pastagens foram abandonadas e se transformaram em capoeiras e, em consequência, através da regeneração em matas secundárias (Miguel, 2009).

Coberturas do solo menos conservacionistas (agricultura) foram substituídas por coberturas de menor potencial erosivo (campo e floresta), especialmente nos locais de maior valor do fator LS, como as áreas declivosas do rebordo do planalto, localizadas entre as linhas tracejadas das Figuras 3A, 3B e 3C. Segundo Minella et al. (2008) os maiores contribuintes para a produção de sedimentos são as áreas em cultivo agrícola, canais da rede de drenagem e estradas, principalmente aquelas construídas na direção do declive.

Devido à variabilidade espacial e temporal da paisagem e do uso da terra, custos com mão-de-obra e o tempo necessário para a coleta de dados, existem dificuldades na implementação de metodologias de mensuração da erosão em extensas áreas utilizando-se de métodos convencionais (Yue-Qing et al., 2008). Este estudo demonstrou que o RUSLE é perfeitamente aplicável para a quantificação da erosão bruta em uma bacia hidrográfica, apontando as áreas de maior possibilidade para a ocorrência deste fenômeno, possibilitando o direcionamento dos recursos para sua mitigação.

As limitações desse estudo estão ligadas ao próprio uso do RUSLE, um modelo originalmente concebido para aplicações em áreas agrícolas em situações semelhantes daquelas das parcelas experimentais e que, neste caso, foi implementado em uma bacia hidrográfica. O RUSLE não considera questões relacionadas à umidade do solo e hidrologia da paisagem, ambas muito importantes para a erosão da paisagem (Kinnell, 2010). Apesar de, qualitativamente, indicar o potencial erosivo da paisagem, o conhecimento acurado e espacializado da erosão dependerá da determinação adequada dos parâmetros da equação. Simplificações como as que foram feitas neste estudo, quanto ao fator práticas de manejo do solo, podem estar afetando, sobremaneira, os valores da perda de solos média anual.

Em estudos futuros pode-se buscar quantificar as mudanças ocorridas nas propriedades rurais, associando-as à localização espacial e aos valores dos fatores empregados no modelo RUSLE. Informações a respeito dos cultivos implantados e das práticas de manejo adotadas, poderiam indicar melhor como as mudanças experimentadas pela agricultura, mais acentuadamente no final do século 20 (Perestrelo \& Martins, 2003), têm afetado a produção de sedimentos.

\section{CONCLusões}

1. Durante o período de 1988 a 2007 ocorreu uma substituição de áreas ocupadas por agricultura por usos mais conservacionistas, como o campo e a floresta. As áreas inicialmente sob agricultura sofreram uma redução de $57,5 \%$, ao passo que as florestas aumentaram em 16,2\% indicando uma desintensificação do uso da terra.

2. O aumento de coberturas de maior poder de conservação do solo representou uma diminuição da erosão bruta em $44 \%$ ao longo do período de 19 anos. 
3. A diminuição da perda de solos média por unidade de área em decorrência da erosão está associada à substituição do uso da terra, ocorrida nas áreas de encosta, as quais têm grande poder erosivo.

\section{LITERATURA CITADA}

Albuquerque, A. W. de; Moura Filho, G.; Santos, J. R.; Costa, J. P. V.; Souza, J. L. Determinação de fatores da equação universal de perda de solo em Sumé, PB. Revista Brasileira de Engenharia Agrícola e Ambiental, v.9, p.153-160, 2005.

Angima, S. D.; Stott, D. E.; O’Neill, M. K.; Ong, C. K.; Weesies, G. A. Soil erosion prediction using RUSLE for central Kenyan highland conditions. Agriculture, Ecosystems \& Environment, v.97, p.295-308, 2003.

Bakker, M. M.; Govers, G.; Doorn, A. van; Quetier, F.; Chouvardase, D.; Rounsevell, M. The response of soil erosion and sediment export to land-use change in four areas of Europe: The importance of landscape pattern. Geomorphology, v.98, p.213-226. 2008.

Cebecauer, T.; Hofierka, J. The consequences of land-cover changes on soil erosion distribution in Slovakia. Geomorphology, v.98, p.187-198, 2008.

Dill, P. R. J.; Paiva, E. M. D.; Paiva, J. B. D.; Rocha, J. S. M. Assoreamento do Reservatório do Vacacaí-Mirim em Santa Maria e a sua relação com a deterioração da Bacia Hidrográfica contribuinte. Revista Brasileira de Recursos Hídricos, v.9, p.56-64, 2004.

Kinnell, P. L. A. Event soil loss, runoff and the universal soil loss equation family of models: A review. Journal of Hidrology, v.385, p.384-397. 2010.

Kinnell, P. L. A.; Risse, L. M. USLE-M: Empirical modeling rainfall erosion through runoff and sediment concentration. Soil Science Society American Journal, v.62, p.1667-1672, 1998.

Klamt, E.; Dalmolin, R. S. D.; Cabral, D. da R. Solos do município de São João do Polêsine: Classificação, distribuição geográfica e aptidão de uso. Santa Maria: CCR, Departamento de Solos, 1997.93p.

Miguel, P. Caracterização pedológica, uso da terra e modelagem da perda de solo em áreas de encosta do Rebordo do Planalto do RS. Santa Maria: UFSM, 2009. 112p. Dissertação Mestrado

Minella, J. P. G.; Merten, G. H.; Reichert, J. M.; Santos, D. R. dos. Identificação e implicações para a conservação do solo das fontes de sedimentos em bacias hidrográficas. Revista Brasileira de Ciência do Solo, v.31, p.1637-1646, 2007.

Minella, J. P. G.; Walling, D. E.; Merten, G. H. Combining sediment source tracing techniques with traditional monitoring to assess the impact of improved land management on catchment sediment yields. Journal of Hydrology, v.348, p.546-563, 2008.
Moore, I. D.; Gessler, P. E.; Nielsen, G. A.; Peterson. G. A. Soil attribute prediction using terrain analysis. Soil Science Society American Journal, v.57, p.443-452. 1993.

Morgan, R. P. C. Soil erosion and conservation. Victoria: Blackwell Publishing, 2005, 3.ed, 320p.

Okalp, K. Soil erosion risk mapping using geographic information systems: A case study on Kocadere Creek watershed, Izimir. Ankara, Turkey,: Middle East Technical University 2005. 124p. Master of Science Dissertation

Pedron, F. A.; Poelking, E. L.; Dalmolin, R. S. D.; Azevedo, A. C.; Klamt, E. Aptidão de uso da terra como base para o planejamento da utilização dos recursos naturais no município de São João do Polêsine-RS. Ciência Rural, v.36, p.105-112, 2006.

Perestrelo, J. P. P.; Martins, I. S. Modernização rural: Transformações econômicas e suas implicações demográficas, epidemiológicas e nutricionais nos municípios de Monteiro Lobato e Santo Antônio do Pinhal. Saúde e Sociedade, v.12, p.38-55, 2003.

Ruhoff, A. L. Gerenciamento de recursos hídricos em bacias hidrográficas: Modelagem ambiental com a simulação de cenários preservacionistas. Santa Maria: UFSM, 2004. 93p. Dissertação Mestrado

Santos, C. N. dos. El Niño, La Niña e a erosividade das chuvas no Estado do Rio Grande do Sul. Pelotas: UFPel, 2008. 138p. Tese Doutorado

Schiettecatte, W.; D’Hondt, L.; Cornelis, W. M.; Acosta, M. L.; Leal, Z.; Lauwers, N.; Almoza, Y. ; Alonso, G.R.; Díaz, J.; Ruíz, M.; Gabriels, D. Influence of landscape on soil erosion risk in the Cuyaguateje watershed (Cuba). Catena, v.74, p.1$12,2008$.

Stürmer, S. L. K.; Dalmolin, R. S. D.; Azevedo, A. C.; Pedron, F. A.; Menezes, F. P. Relação da granulometria do solo e morfologia do saprolito com a infiltração de água em Neossolos Regolíticos do Rebordo do Planalto do Rio Grande do Sul. Ciência Rural, v.36, p.2057-2064, 2009.

Vanacker, V.; Molina, A.; Govers, G.; Poesen, J.; Dercon, G.; Deckers, S. River channel response to short-term humaninduced change in landscape connectivity in Andean ecosystems. Geomorphology, v.72, p.340-353, 2005.

Wischmeier, W. H.; Smith, D. D. Predicting rainfall-erosion losses: a guide to conservation planning. Agriculture Handbook. USDA: Washington. v.537, 1978, 58p.

Yue-Qing, X.; Xiao-Mei, S.; Xiang-Bin, K.; Jian, P.; Yun-Long, C. Adapting the RUSLE and GIS to model soil erosion risk in a mountains karst watershed, Guizhou Province, China. Environment Monitoring Assess, v.141, p.275-286, 2008. 